\title{
SEROPREVALENCE OF TRANSFUSION TRANSMITTED INFECTIONS IN NORTH COASTAL REGION OF ANDHRA PRADESH- 3 YEARS STUDY
}

\author{
Jagadeeswari Suvvari ${ }^{1}$, Papa Ratnam Kalivarapu²
}

1Assistant Professor, Department of Pathology, Rajiv Gandhi Institute of Medical Sciences, Srikakulam, Andhra Pradesh.

${ }^{2}$ Associate Professor, Department of Pathology, Rajiv Gandhi Institute of Medical Sciences, Srikakulam, Andhra Pradesh.

\begin{abstract}
BACKGROUND
ABSTRACT

Blood transfusion services save millions of lives, but these services are associated with large number of complications, some are trivial, and some are life-threatening. So strict criteria should be followed while selecting the donor and screening of Transfusion Transmitted Infections. Blood transfusion services not only screen the blood donor, but also give a clue about the rate of prevalence of TTD in asymptomatic healthy young adults.

Objective- Descriptive study of the seroprevalence of Transfusion Transmitted Infections among blood donors at Blood Bank, RIMS, Govt. Hospital, Srikakulam, Andhra Pradesh during a period of three years, i.e. from Jan. 2015 to Dec. 2017.
\end{abstract}

\section{MATERIALS AND METHODS}

This is a descriptive study. All blood donation samples, which are collected during this 3-year period were screened for five mandatory tests, i.e. HIV; HBV; HCV; Syphilis and Malaria.

\section{RESULTS}

Total 12,314 units of blood was collected in voluntary blood donation camps and in-house donations over a period of three years, out of which 39 (3.17\%) units were found to be seropositive for Transfusion Transmitted Infections. Seropositivity for HBV (68.8\%) is predominant Transfusion Transmitted Infection followed by HCV (19.4\%) and HIV (9.2\%). Prevalence is seen in the age group of 21 to 30 years (53.2\%) and in replacement donors (6.81\%) (206).

\section{CONCLUSION}

All blood donations should be strictly screened for Transfusion Transmitted Infections to facilitate safe blood supply to needy patients. So strict selection criteria for donor is a must and use of sensitive screening tests for Transfusion Transmitted Infections reduces the incidence and prevalence of Transfusion Transmitted Infections. Voluntary donations should be encouraged to reduce TTIs among replacement donors.

\section{KEYWORDS}

Prevalence, Transfusion Transmitted Infections, Voluntary Donor, HIV; HBV; HCV; Syphilis.

HOW TO CITE THIS ARTICLE: Suvvari J, Kalivarapu PR. Seroprevalence of transfusion transmitted infections in North Coastal region of Andhra Pradesh- 3 years study. J. Evolution Med. Dent. Sci. 2018;7(10):1252-1254, DOI: 10.14260/jemds/2018/285

\section{BACKGROUND}

Blood transfusion services save millions of lives, but unsafe transfusion practices put millions of people at risk of Transfusion Transmitted Infections. Even after development of medical science to such an extent, we do not have any substitute for blood till now. Prevention of Transfusion Transmitted Infections through blood transfusion in developing countries is difficult because of the unavailability of tests to detect the disease in window period, lack of trained personnel, immune-silent carriers and accidental laboratory testing errors. The prevalence of transfusion-transmissible infections in blood donations in high-income countries is considerably lower than in low- and middle-income countries.

As per guidelines of The Ministry of Health and Family Welfare and Drug and Cosmetic Act 1945, all the donated

'Financial or Other Competing Interest': None.

Submission 17-01-2018, Peer Review 13-02-2018,

Acceptance 21-02-2018, Published 05-03-2018.

Corresponding Author:

Dr. Papa Ratnam Kalivarapu,

Plot No. 195/B, Govind Nagar,

Near Old Abhyudaya Degree College,

Srikakulam-532001.

E-mail: paparatnam09@gmail.com

DOI: $10.14260 /$ jemds $/ 2018 / 285$

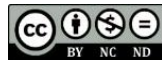

blood units were to be mandatorily screened for five major infections namely HIV 1 and 2, HBsAg, HCV, syphilis and malaria. Blood transfusion services not only screen the blood donor, but also give a clue about the rate of prevalence of TTD in asymptomatic healthy young adults. Apparently, healthy blood donors might carry out transfusion transmitted infections which might be fatal for the donor himself as well as the recipient later on.

Donors who were tested positive for any of these TTIs, they were allowed to be retested with fresh blood sample and if they were again found to be positive referred them to ICTC centres for HIV testing, counselling and for medication. Hepatitis B and C positive donors to Gastroenterologist and syphilis positive donors to RTI department for further management and they should be educated and restrained from blood donation. Positive blood units are to be discarded as per Biomedical Waste Guidelines.

The magnitude of the TTI varies from country to country depending on TTIs' loads in that particular population from where blood units are sourced.

\section{MATERIALS AND METHODS}

This is a descriptive study for a period of three years, i.e. from January 2015 to December 2017 carried out in the Blood Bank, RIMS General Hospital, Srikakulam, Andhra Pradesh. Donors were selected by the standard criteria for donors by 
NACO. All samples were screened for all five mandatory tests, i.e. HIV 1 and 2, HBsAg, HCV, syphilis and malaria. All these tests were performed by trained technician under supervision of blood medical officer.

Screening for HIV 1 and 2, HBsAg and HCV were done by manual Robonik Elisa Reader, syphilis by RPR kits and malaria by microscopic examination of thick and thin smears-

- HIV- $3^{\text {rd }}$ generation and $4^{\text {th }}$ generation kits of ERBA (Transasia) and SD manufactures.

- HbsAg- ERBA (Transasia).

- HCV- SD kits.

- $\quad$ Syphilis- Tulip RPR kit.

- Malaria- JSB stain and Leishman's Stain.

\section{RESULTS}

Total 12,314 units of blood was collected in voluntary blood donation camps and in-house donations over a period of three years at Blood Bank, RIMS, Srikakulam, of which 9,293 (75.46\%) units were collected from voluntary donors and 3021 (24.54\%) were from replacement donors (Table No. 1).

Seropositivity for mandatory testing for Transfusion Transmitted Infections was detected in 391 blood units, out of total 12,314 units comprising of $3.17 \%$. Incidence of seropositivity in voluntary donations is $1.99 \%$ (185) and $6.81 \%$ (206) in replacement donors (Table 2).

The seropositivity was mostly seen in the age group of 21-30 years (53.2\%) (Table No. 3 ).

Out of 391 seropositive blood units, HIV 1 and 2 was detected in 36 units (9.2\%), HbsAg in 269 units (68.8\%), HCV in 76 units (19.4\%), Syphilis in 9 units (2.3\%), malaria in 1 unit $(0.2 \%)$ (only one case of malaria was detected during analysis period) (Table No. 4).

\begin{tabular}{|l|c|c|c|c|c|c|c|c|c|c|c|}
\hline & Total & HIV & $\mathbf{\%}$ & HBsAg & $\mathbf{\%}$ & HCV & $\mathbf{\%}$ & VDRL & \% & Malaria & \% \\
\hline 2015 & 3956 & 15 & 0.37 & 80 & 2.02 & 32 & 0.80 & 6 & 0.15 & 1 & 0.02 \\
\hline 2016 & 4393 & 09 & 0.20 & 101 & 2.29 & 40 & 0.91 & 3 & 0.06 & 0 & - \\
\hline 2017 & 3965 & 12 & 0.30 & 88 & 2.22 & 4 & 0.10 & 0 & -- & 0 & - \\
\hline \multicolumn{8}{|c|}{ Table 4. TTI- Number of Cases and Percentages Year Wise } \\
\hline
\end{tabular}

\begin{tabular}{|c|c|c|c|c|c|c|}
\hline State & Author & $\begin{array}{c}\text { HIV } \\
\%\end{array}$ & $\begin{array}{c}\text { HBsAg } \\
\%\end{array}$ & $\begin{array}{c}\text { HCV } \\
\%\end{array}$ & $\begin{array}{c}\text { VDRL } \\
\%\end{array}$ & \begin{tabular}{|c} 
Malaria \\
$\%$
\end{tabular} \\
\hline $\mathrm{MP}^{1}$ & $\begin{array}{c}\text { Bhagwan } \\
\text { Singh } \\
\text { Yadav } \\
\text { et al }\end{array}$ & 0.14 & 1.77 & 0.09 & 0.04 & 0 \\
\hline Karnataka $^{2}$ & $\begin{array}{c}\text { Kirana } \\
\text { Pailoor } \\
\text { et al }\end{array}$ & 0.44 & 1.27 & 0.23 & 0.28 & 0 \\
\hline Jharkhand $^{3}$ & $\begin{array}{c}\text { Shalini } \\
\text { Sunderam } \\
\text { et al }\end{array}$ & 0.08 & 1.01 & 0.14 & 0.03 & 0.33 \\
\hline Rajasthan 4 & $\begin{array}{c}\text { Dev Raj } \\
\text { Arya } \\
\text { et al }\end{array}$ & 0.10 & 1.60 & 0.18 & 0.89 & 0.04 \\
\hline Haryana $^{5}$ & $\begin{array}{c}\text { Arora D } \\
\text { et al }\end{array}$ & 0.3 & 1.7 & 1.0 & 0.9 & 00 \\
\hline $\begin{array}{l}\text { Present } \\
\text { Study }\end{array}$ & & 0.29 & 2.18 & 0.61 & 0.07 & 0.008 \\
\hline
\end{tabular}

\section{Table 5. Comparative Study-State Wise/Percentage Wise}

\section{DISCUSSION}

With over approximately 112.5 million (WHO Studies) blood units collected over a year throughout the world, Transfusion Transmitted Infections are subject of concern. WHO
Thus, out of 391 TTI seropositive blood units, the commonest Transfusion Transmitted Infection was HBsAg followed by HCV and HIV. Least common Transfusion Transmitted Infection was malaria.

\begin{tabular}{|c|c|c|c|}
\hline & Total & VD & RD \\
\hline 2015 & 3956 & 2851 & 1105 \\
\hline 2016 & 4393 & 3527 & 866 \\
\hline 2017 & 3965 & 2915 & 1050 \\
\hline Grand Total & $\mathbf{1 2 3 1 4}$ & $\mathbf{9 2 9 3}$ & $\mathbf{3 0 2 1}$ \\
\hline Table 1. Total Number of Voluntary and Replacement \\
Donors \\
\hline
\end{tabular}

\begin{tabular}{|c|c|c|c|}
\hline & VD & RD & Total \\
\hline 2015 & 59 & 75 & 134 \\
\hline 2016 & 57 & 96 & 153 \\
\hline 2017 & 69 & 35 & 104 \\
\hline Grand Total & $\mathbf{1 8 5}$ & $\mathbf{2 0 6}$ & $\mathbf{3 9 1}$ \\
\hline \multicolumn{3}{|c|}{ Table 2. Incidence of TTIS in Voluntary and } \\
Replacement Donors \\
\hline
\end{tabular}

\begin{tabular}{|c|c|c|c|}
\hline Age & 2015-134 & $\mathbf{2 0 1 6 - 1 5 3}$ & 2017-104 \\
\hline $15-20$ & 29 & 25 & 17 \\
\hline $21-30$ & 66 & 88 & 54 \\
\hline $31-40$ & 22 & 24 & 25 \\
\hline $41-50$ & 17 & 13 & 7 \\
\hline $51-60$ & 0 & 3 & 1 \\
\hline \multicolumn{4}{|c|}{ Table 3. TTI- Age and Year Wise Distribution } \\
\hline
\end{tabular}

recommends that all blood donations should be screened for infections prior to use.

Newer strategies are to be adopted in order to minimise transfusion transmitted infections and provide safer blood product, as there is change in population dynamics. Hence, National Haemovigilance System should be enrolled in all the health care set-ups including both Private and Government Medical Colleges to provide safer blood products.

In our study prevalence of transfusion transmitted infections (HIV, HBV, HCV, VDRL and malaria) was higher in replacement donors in comparison to voluntary donors, which is correlating with the study done by Bhagwan Singh Yadav et al ${ }^{1}$ and Dev Raj Arya et al. ${ }^{4}$

The prevalence of HIV has been decreasing in the Indian population supporting the growing awareness of this lifethreatening diseases. Prevalence of HIV (0.29\%) in our study at par with all other studies.1,2,3,4,5

HBsAg infection still continues to be a menace to the society, because in spite of decreasing trend incidence of the disease is still very high in general population. In our study, HBV prevalence is high $(2.8 \%)$ when compared with other studies. ${ }^{1,2,3,4,5}$ 
Prevalence of HCV infection in our study was $0.61 \%$, which is comparable to all studied except Arora et al (1\%).

Prevalence of syphilis infection in our study was $0.07 \%$, which was comparable with studies done by Yadav et al and Sunderam $S$ et al.

\section{CONCLUSION}

Voluntary donations are safer as compared to replacement ones and should be encouraged. Transmission of TTIs during serologically negative window period is still a threat to blood safety. Therefore, strict selection of blood donors and comprehensive screening of donor's blood using standard methods are highly recommended to ensure the safety of blood for recipient. For prevention of TTDs, healthy VBD recruitment and safe VBD retention strategies should be strengthened at all levels in blood transfusion service.

It has been concluded that prevalence of transfusion transmitted infection (HIV, HBV, HCV, VDRL and malaria) was higher in replacement donors in comparison to voluntary donors.

\section{REFERENCES}

[1] Yadav BS, Varma AV, Singh P, et al. Sero-prevalence of transfusion transmitted infections [TTIs] in blood donors: a study from Central India. Int J of Med Sci Public Health 2016;5(6):1-5.

[2] Pailoor K, Keshava SM, Rai P, et al. A retrospective study of screening of common transfusion transmitted infections in the blood bank of a tertiary care centre. J Blood Disord \& Transfusion 2015;6:267.

[3] Sunderam S, Karir S, Haider S, et al. Sero-prevalence of transfusion transmitted infections among blood donors at blood bank of Rajendra Institute of Medical Sciences, Ranchi. Healthline Journal 2015;6(1):36-40.

[4] Arya DR, Mahawar NL, Pactury R, et al. Seroprevalance of transmitted influence among blood donors at a Tertiary Care hosipital Blood Bank in North India. India J Health Sci \& Biomed Res 2016;9(1):77-81.

[5] Arora D, Arora B, Khetarpal A. Seroprevalence of HIV, HBV, HCV and syphilis in blood donors in southern Haryana. Indian J Pathol Microbiol 2010;53(2):308-9. 